\title{
El arte despierta al mundo. Una conversación con Shantala Shivalingappa
}

\author{
Irene López Arnáiz ${ }^{1}$ \\ Universidad Complutense de Madrid \\ ilarnaiz@ucm.es
}

Shantala Shivalingappa, nacida en Chennai (India) y criada en París, es una de las bailarinas de danza clásica india con mayor proyección internacional, al tiempo que una figura fundamental del panorama de la danza contemporánea. Sus creaciones se sitúan en una suerte de encrucijada entre Oriente y Occidente. En ellas convergen distintas formas de expresión corporal, fruto inevitable de su trayectoria personal y del modo de entender su trabajo desde el respeto y la profunda comprensión de cada uno de los estilos y géneros en los que se ha introducido. El mestizaje y la transdisciplinariedad, tan en boga en el arte actual, se materializan de manera natural en su cuerpo, en el que las fronteras son dúctiles, inestables y difusas.

Su primera incursión en el terreno de la danza fue el Bharatanātyam que aprendió con su madre, Savitry Nair, también bailarina. Después se sumergió en el Kūcipūọi de la mano de su maestro Vempati Chinna Satyam, del que habla con profundo respeto y admiración ${ }^{2}$. Pero su formación no se limita ni al ámbito de la danza ni al subcontinente indio. A una edad muy temprana trabajó con Peter Brook y Pina Bausch, quienes le transmitieron valiosas lecciones vitales y artísticas que impregnan cada una de sus creaciones. A lo largo de su carrera ha colaborado con otros muchos artistas procedentes de diversas culturas: Maurice Béjart, Bartabas, Ferran Savall o Sidi Larbi Cherkaoui, entre otros. Encuentros, como ella los llama, que han dejado sutiles huellas en cada una de sus piezas tanto de danza contemporánea como de danza india [1].

Me encuentro con ella una calurosa tarde de julio en un tranquilo café del Barrio Latino de París. Nos acompaña Tiziana Leucci, investigadora vinculada al Centre d'études de l'Inde et de l'Asie du Sud (CEIAS, CNRS-EHESS). Leucci, especialista en danza india, vivió durante doce años en Chennai, donde estuvo investigando a nivel teórico y prác-

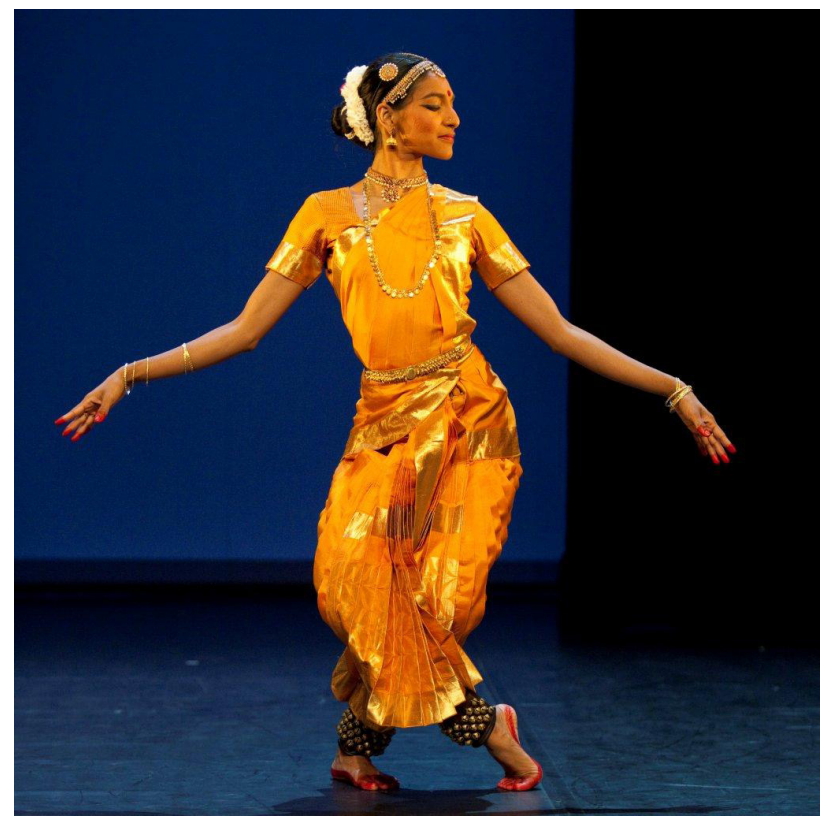

1. Shantala Shivalingappa en Akasha (fotografía de Elian Bachini)

tico sobre el Bharatanātyam y la tradición de las bailarinas ligadas a los templos y a la corte.

Nada más llegar, Shantala Shivalingappa se muestra como una persona accesible y cercana. Se acomoda, con un expresivo silencio nos muestra que está dispuesta a ofrecernos su tiempo. A pesar de su juventud, Shantala ha desarrollado una dilatada carrera artística sobre la que habla con profunda humildad. Sus reflexiones surgen casi siempre acompañadas de gestos precisos y delicados y de una expresividad difícilmente descriptible que la delatan como bailarina. Con una sencillez asombrosa, transmite con cada una de sus respuestas su enorme curiosidad y su extraordinaria sensibilidad hacia la danza, hacia el arte y hacia el mundo. 


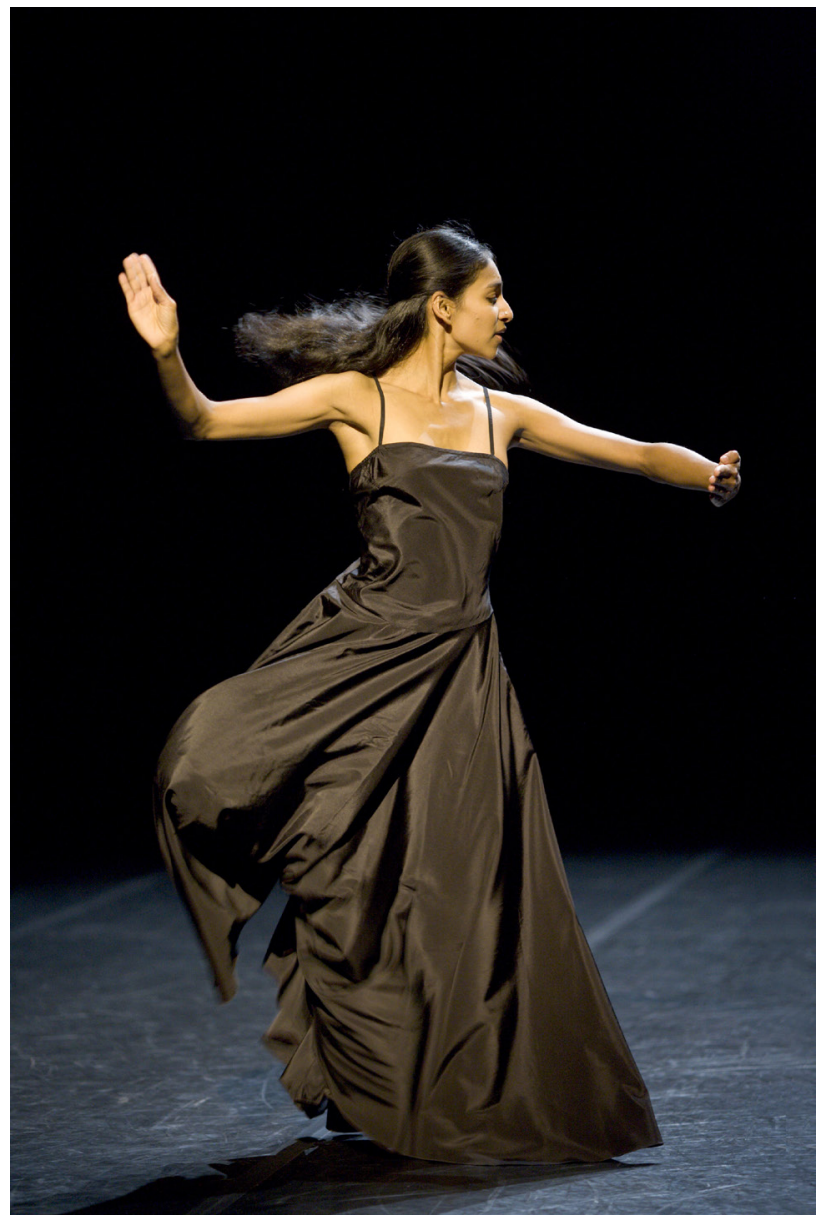

2. Shantala Shivalingappa en Namasya (fotografía de Laurent Philippe)

Me gustaría comenzar evocando la figura de tu maestro de Kūcipūọi, aquello que te ha transmitido y la particular relación que se establece en India con el gurú.

La personalidad del gurú es fundamental. Lo observamos constantemente, es nuestro ejemplo, queremos ser como él en todo, en el modo de hablar, de comportarnos y evidentemente en la manera de bailar. Tradicionalmente no es solo el transmisor de una técnica o de un saber, es también la persona que te forma como ser humano, debe encarnar cualidades humanas y morales muy poderosas.

Mi maestro, Vempati Chinna Satyam, lo fue también de mi madre. Es una persona muy carismática. En mi relación con él había un enorme respeto, mucho amor, admiración. También su hijo ha sido una figura primordial para mí. Mi maestro ya prácticamente no bailaba, así que aprendí mu- cho observando a su hijo, un bailarín excepcional. En India aprendemos por la observación, miramos y reproducimos, no hay explicación. Hacemos el mismo paso durante mucho tiempo y en cierto momento comenzamos a entender algo.

Siendo muy joven has trabajado también con Peter Brook y Pina Bausch. ¿Podrías comparar, en cierta manera, estas figuras con la de Vempati Chinna Satyam?

Tengo el mismo respeto, admiración, fascinación, amor por todos ellos, por lo que, en este sentido, creo que son absolutamente comparables. Todos me han transmitido enseñanzas extremadamente refinadas, sutiles, ricas, profundas como un océano. Aunque no he estudiado ninguna técnica codificada específica con Pina Bausch o con Peter Brook, he aprendido mucho de ellos. Por lo que sí, puedo decir que he tenido varios maestros.

\section{¿Cómo empezaste a trabajar con Pina Bausch? ¿Fue por azar?}

No hay azares en la vida. Mi madre ha sido como una buena estrella, ha guiado toda mi vida. Nací, ella era bailarina, así que empecé a bailar. Al poco tiempo nos trasladamos a Francia donde conoció a muchos artistas muy interesantes, entre ellos Pina Bausch y Peter Brook. Pina y ella eran muy amigas. Cuando era pequeña la conocí primero como amiga de la familia. Cuando hice mi primera gira de Kücipūọi en Europa con mi maestro, Pina nos invitó a Wuppertal, tuvimos un encuentro precioso y organizamos talleres para su compañía. Un día me invitó a comer, las dos solas, y me preguntó si quería hacer una pieza con su compañía. Dije que sí, pero fue porque le tenía cariño, todavía no conocía verdaderamente su trabajo, no llegaba a situarlo. Había visto sus espectáculos, todo me parecía una locura, pasaban muchas cosas. No pude decirle que no. Así fue.

\section{Y, ¿cómo fue tu experiencia trabajando con ella?}

Cuando comencé a trabajar con ella, aunque había visto muchos tipos de danza, pues he crecido en Francia, como experiencia propia, sólo tenía la danza india. Estaba completamente perdida, yo venía de una tradición extremadamente codificada, pero con Pina empezábamos a producir movimiento sin ningún vocabulario predeterminado. Era un momento en que yo comenzaba a dominar la técnica del Kūcipūọi y aquello me empujó hacia nuevas direcciones. 
3. Shantala Shivalingappa (fotografía de Rodrigo Cesa)

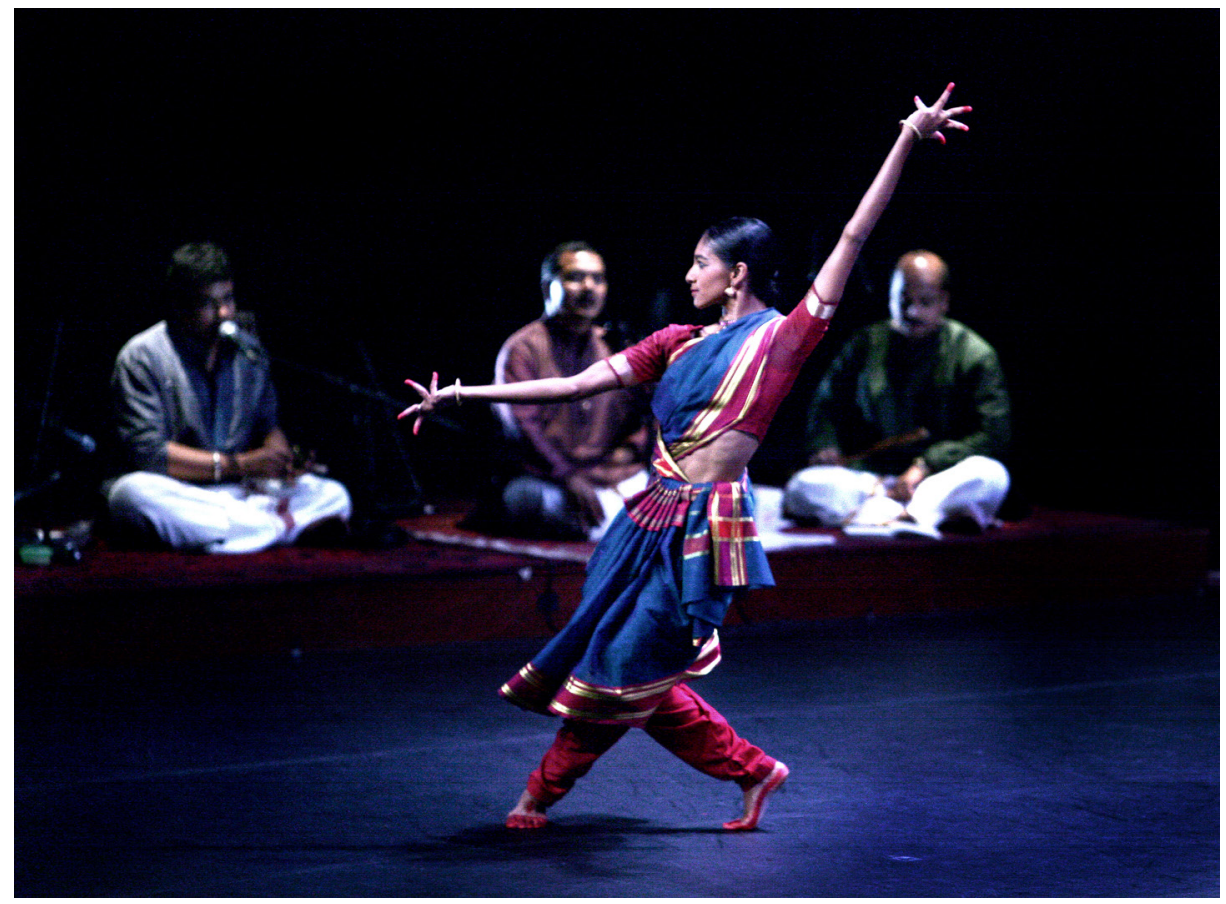

Creo que es muy importante introducirnos en ambientes en los que nos sentimos sin nada, siempre es peligroso considerarse maestro de una disciplina.

La compañía de Pina genera un espacio en el que uno se siente muy protegido en compañía de bailarines extraordinarios. Gran parte de mi experiencia con Pina ha sido observarla a ella y a sus bailarines, pero para nada de una manera intelectual. Consistía en absorber, en impregnarse. Uno de los momentos clave fue aprender La Consagración de la Primavera. Esta coreografía fue como una formación en su técnica, pues no tenía nada que ver con mi gestualidad. Aprendí algo que no fue creado específicamente para mí y que poseía movimientos muy poderosos que nos introducen de lleno en su gestualidad. Para mí, esta pieza y todo el trabajo que hay en torno a ella ha sido una formación complementaria al Kücipūọdi, ha influido en todo lo que he hecho después, así como en mi comprensión del movimiento [2].

Dices que el trabajo con Pina Bausch ha influido mucho en todo lo que has hecho. Supongo que no sólo en tus piezas contemporáneas, ¿también en la danza india?

Evidentemente. Todo se encuentra. Es como un río, hay mucha agua que viene de todas partes, pero finalmen- te todo corre en una misma dirección. (Shantala gesticula con sus manos el agua que viene de distintos lugares hasta alcanzar el mismo cauce). Para mí, esa misma dirección es todo lo que hacemos, en la danza, pero también como seres humanos, pues ambos son indisociables, forman parte de un mismo conjunto.

La intención primordial de la danza india, y de todas sus artes, es celebrar la energía universal que está en nosotros. Celebrarla y también entrar en contacto con ella, buscar el contacto visible, concreto, con nuestro cuerpo y con nuestro interior. Mi maestro insistía en que bailar no consiste sólo en gesticular. Cuanto más refinamos la forma propiciamos el mismo efecto en nuestro interior. Este es el camino. Y todas mis experiencias con mis maestros tienen en común la búsqueda del refinamiento del ser.

Entonces, cuando compones piezas de Kūcipūọi o de danza contemporánea empleas, no quiero decir el mismo método, pero... ¿la misma disposición, el mismo espíritu?

Sí, lo has expresado bien, porque creo que no hay un método. Hay un estado del espíritu. Lo que intento es cultivar un estado de apertura, de receptividad a una energía 
que intenta penetrar, sin resistirse ni encerrarse. Para mí el trabajo consiste en esto: en pulir, precisar, reforzar el medio físico y en hacer lo mismo al resto de niveles.

\section{Me pregunto cómo es posible trabajar de esta manera en una disciplina con un lenguaje tan codificado como la danza clásica india. Hay quien piensa que el arte clá- sico, y las danzas indias particularmente, tienen algo de inmutable. ¿Cuál es tu aproximación al Kūcipūọi en este sentido?}

Tienes razón. Lamentablemente, a menudo tenemos la sensación de que las artes clásicas, y sobre todo las antiguas, son muy rígidas. Pero creo que es una impresión falsa. Si estas artes han llegado hasta nuestros días es porque son lo suficientemente maleables como para atravesar el tiempo. Creo que cada intérprete reinventa. Mi maestro ha innovado enormemente hasta llegar a recodificar el Kūcipūdili. Así que, cuando aprendí este estilo, lo hice con este acercamiento que intenta estar abierto al mundo, impregnándose de todas las cosas inspiradoras, bellas, que nos hablan y nos conmueven.

Todos los estilos clásicos son muy permeables. En un primer momento hay que entrar muy profundamente en el Kūcipūdi. Este acercamiento puede llevarnos toda la vida, pero a veces llega un momento en que comenzamos a sentir que estamos impregnados por este estilo, como si nuestro cuerpo se hubiera convertido en un molde de Kūcipūdili. Cuando hago un movimiento que procede de otra influencia termina por asimilarse a este estilo. No tiene sentido pensar que las cosas son herméticas y rígidas. Creo que la vida funciona así, nutriéndose de distintas cosas, todo está en relación constante, evolucionamos todo el tiempo. Esta es la regla de la Vida con mayúscula. Esto no contradice que la danza clásica india tenga una identidad muy precisa, pero solo puede ganar al ser inyectada con nuevas energías, manteniendo siempre el respeto por la expresión de este estilo [3].

En India actualmente hay un gran debate sobre el aspecto mitológico de la danza. Dicen que la mitología está muy anticuada, que hay que interesarse por las cosas de hoy en día y hablar de los problemas sociales y políticos. Esto se puede hacer con otras cosas, pero no con este arte. El propósito de la danza india, desde el primer momento, no es hablar del ahora, sino abrir una ventana para tener con- tacto con algo diferente, para sacarnos de donde estamos y trasladarnos a otra dimensión más abierta, más universal. Es cierto que las historias mitológicas de los personajes son muy específicas, pero también son arquetipos, energías que encarnan cualidades humanas muy poderosas que todo el mundo puede comprender. Esto es lo que me interesa. Cuando interpreto a Śiva, lo que quiero no es contar una historia que puede ser fascinante, interesante, sino encarnar su energía e intentar comunicarla. Esto es universal, no es antiguo ni nuevo; el ser humano no cambia, tenemos las mismas emociones, vivimos las mismas cosas. Creo que la función de la danza de ofrecer una ventana hacia otra dimensión interior y colectiva sigue siendo muy importante, seguimos teniendo esta necesidad.

\section{Me gustaría volver al tercero de tus maestros, ¿cómo ha sido tu experiencia con Peter Brook?}

He trabajado dos veces con él, la primera como Miranda, con catorce años. Fue un gran descubrimiento. No tenía verdadera consciencia de lo que hacíamos, era muy joven e ingenua, pero me fascinaba todo lo que pasaba. Creo que aprendí muchísimo, pero sin saberlo, de nuevo, a partir de la observación. Observar, escuchar son algunas de las cosas que me han quedado. Y también una cierta liberación, trabajar en grupo, lanzarte a hacer cosas a veces ridículas, no saber muy bien qué hacer, improvisar... Es una mezcla de situaciones en las que te sientes muy poco segura, pero todo el mundo participa. Esto me ha animado a desprenderme de ciertas inhibiciones, de muchas cosas que cargamos sobre nosotros. Me ha enseñado que no estamos aquí para encerrarnos en nosotros mismos, sino para trabajar, avanzar y aprender. Si nos protegemos no aprendemos nada.

En la segunda experiencia, con Hamlet (2000), tenía veinticinco años y por ello fui mucho más consciente del proceso. Recuerdo que me fascinó el trabajo con la voz. Empecé a entender que es un instrumento con infinitas posibilidades.

Una de las cosas que todavía me fascinan de Peter es la claridad de su pensamiento, tan límpido, tan simple. Su manera de ver las cosas de una forma casi infantil tiene una fuerza increíble. Y también su atención, su escucha. Hay infinitas cosas que nos ha transmitido y que he retenido. Todas ellas las puedo aplicar a la danza y también a la vida. Intentar buscar la sencillez en la estética, en la interpretación, no es 


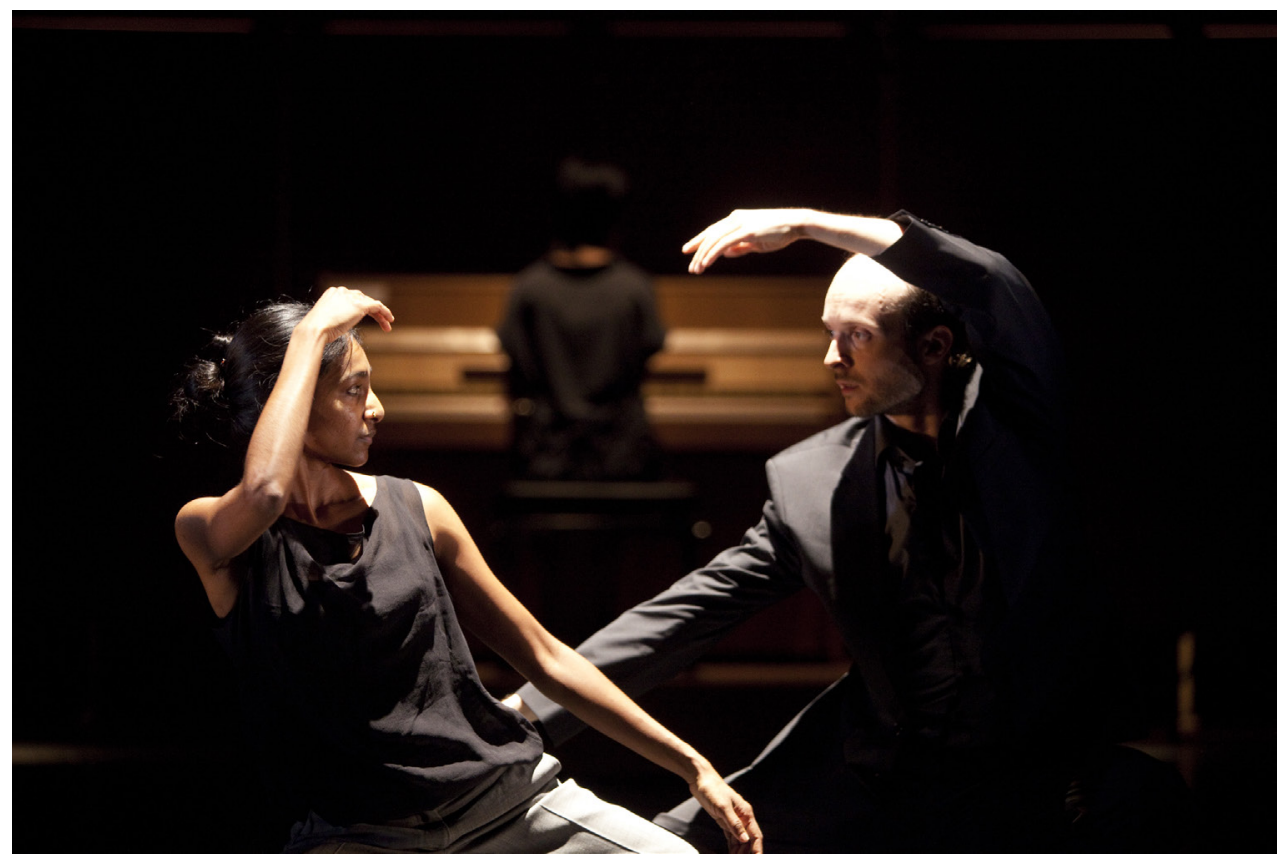

4. Shantala Shivalingappa y Sidi Larbi Cherkaoui en Play (fotografía de Koen Broos)

fácil, pero es algo muy necesario, muy valioso. $Y$ he visto algo parecido en Pina: ir siempre a lo esencial.

El trabajo con Peter me ha marcado profundamente. Nos decía que no hay que introducir ninguna emoción en lo que decimos, sino que debemos intentar decirlo lo más honestamente posible y de este modo la emoción surge. Con la danza india ocurre algo similar, aunque la codificación y la técnica de la expresividad son muy precisas, no deben ser más que simples herramientas. Aplicando la lección de Peter, creo que es la claridad en la estructura de estas herramientas la que hace surgir la emoción. Recuerdo también que una vez nos dijo que cuando tenemos que hacer una elección, hay que explorar todas las opciones lo más apasionadamente posible, y después, la elección se hace sola. También incidía en la importancia del humor y de la ligereza. Hay que tomarse muy en serio el trabajo, pero no tomarse demasiado en serio a uno mismo. Creo que esto es un equilibrio muy importante que hay que encontrar.

En este momento estás en París para interpretar Play con Sidi Larbi Cherkaoui. Me gustaría saber cómo concibes este tipo de colaboraciones con otros bailarines, si buscáis dejaros influir o si se trata, más bien, de una especie de juego, tal y como creo que indica el juego de palabras que da título al espectáculo.

Efectivamente. El juego es el primer acercamiento que tenemos hacia el mundo, pero por desgracia, lo perdemos muy rápido. Cuando somos pequeños jugamos con todo, todo nos fascina, porque el juego es fascinante, es una fuente de alegría y de placer. Pero al mismo tiempo el juego es un aprendizaje, debemos aprender ciertas reglas, a veces debemos desarrollar una técnica, una habilidad, un saber. Para mí es la mejor aproximación que podemos tener hacia el mundo que nos rodea, y si pudiéramos conservarla configuraríamos un mundo totalmente diferente (Sonríe).

Además, el encuentro humano está detrás de todo lo que hacemos, con Larbi y con los músicos que nos acompañan. Cada uno viene con su propio bagaje, con su personalidad. Se produce un encuentro que atraviesa nuestras trayectorias. Abrimos todas las cajas (gesticula como si abriera algo delante de ella) y decimos: «¡He aquí! ¡Tenemos todo esto! ¿Qué hacemos?». Y jugamos, hacemos esto, después esto otro... Al principio no hay reglas, las construimos después [4]. 
Hablas del encuentro humano, y creo que has colaborado con artistas de distintas culturas. ¿Es la danza un medio propicio para conocer y aprender de otras culturas?

Para encontrarse, diría yo, para generar un terreno de encuentro. El lenguaje verbal puede conllevar mucha incomprensión, muchos obstáculos, pero los lenguajes que pasan por otros medios tienen una entrada muy inmediata. Si empezamos a hacer un ritmo (da palmas), si nos miramos a los ojos (me mira a los ojos señalando el encuentro de nuestras miradas con su mano), si hacemos gestos, en seguida... (chasquea los dedos) no hace falta traducción, es instantáneo. Es algo muy primario. Así, el encuentro se produce de inmediato. En cuanto eliminamos el lenguaje verbal nos encontramos. La palabra queda entre nosotros, nos impide el verdadero acercamiento.

Hablabas del juego como el acercamiento al mundo que nunca debemos perder, como una fuente de placer, de alegría, de gozo. ¿Encuentras el juego y el placer cercano a tu concepción del arte?

No solo a mi concepción del arte, creo que la búsqueda fundamental del ser humano es la alegría. Todo el mundo quiere tener, a un cierto nivel, alegría, confort, paz, podemos llamarlo como queramos, pero es lo mismo: bienestar. A nivel animal podríamos decir que tenemos necesidad de comer, de tener un techo y de reproducirnos. Pero cuando estas necesidades están cubiertas, entonces, el mundo entero se convierte en terreno de búsqueda del bienestar. En Play hablamos de esto precisamente. Las artes en India tienen una intención espiritual esencial. ¿Qué es la intención espiritual? Yo diría que el bienestar, el desapego, la unión, la anulación de la diferencia. En definitiva, ser uno, es eso lo que buscamos, que todo se encuentre. En presencia del arte todo el mundo siente la misma energía, todo el mundo vive algo muy poderoso. Esto es la unión, ese momento en el que todas las diferencias son superadas. Cuando comunicamos, expresamos y compartimos nos convertimos en uno solo. Creo que en eso consiste el arte, en la unión, en juntarse, en compartir.

La imagen de la danza como una ventana hacia otra dimensión que evocabas antes, tu visión de ella como algo que trasciende la actualidad, me recuerda a una conocida frase de Matisse en la que dice que el arte debe ser «como un lenitivo, un calmante cerebral, algo parecido a un buen sillón, que relaje [al espectador] de sus fatigas físicas» (2005: 50). ¿Estarías de acuerdo con la visión de Matisse?

(Risas) Sí, lo entiendo bien. "Que le relaje de sus fatigas físicas». Yo diría también que lo despierte. No es tanto esto (se recuesta en su asiento). Es más bien esto lo que nos interesa (con tono de emoción, se reincorpora, abre los brazos y pone cara de sorpresa). Porque si no, nos dormimos, y no queremos que la gente se duerma, al contrario, queremos despertarla. Cuando estamos despiertos lo vemos todo diferente, nuestra percepción del universo cambia y, de repente, el universo cambia también. En la física cuántica está demostrado que el observador cambia e influye en la realidad que observa. Así que, la manera en la que miramos el mundo es el mundo, si podemos llegar a transformar nuestra percepción, es decir, nuestra visión del mundo, entonces, cambiaremos el mundo.

Peter Brook dice que el teatro es como un espejo de la realidad, con la particularidad de que el tiempo teatral es diferente al tiempo de la vida, puesto que podemos alargarlo o condensarlo. Afirma además que el teatro tiene la función de trasladarnos hacia otra dimensión de nosotros mismos, y yo comparto su visión. Cuando me aproximo al arte busco una energía, algo que nos despierte, que nos haga sentir una sensación (pausa). Creo que la palabra wonder lo describe muy bien, no tenemos exactamente un equivalente en francés, no es la sorpresa, es... el asombro ${ }^{3}$. Como bailarina y como espectadora busco el asombro en el arte, quiero ser asombrada por el arte. En ese momento pasamos a un estado de mayor lucidez, estamos mucho más receptivos y somos más conscientes de nuestras sensaciones. Ya no nos rodean todas nuestras preocupaciones, sino que nos encontramos en un espacio abierto en el que somos capaces de sentir, de percibir. Cuando somos niños, todo nos asombra. Antes hablaba del juego, el niño se asombra en su juego. Nosotros hemos perdido esta capacidad de fascinación, todo se ha vuelto falto de interés, ya visto, jamás nos asombramos. Esto nos genera cierta pesadez, tristeza, falta de vida, de alegría. La función del arte consiste en generar ese asombro, algo que creo es esencial.

Tu forma de entender el arte me recuerda a los escritos de Peter Brook (2003: 36; 2010: 112). Creo que los 
dos buscáis ofrecer al espectador un resquicio de vida en vuestras piezas. En el grupo de investigación al que pertenezco hemos reflexionado sobre la vitalidad como algo intrínseco a toda obra artística y sobre la noción de ritmo como aquello que la mantiene con vida. ¿Compartirías este planteamiento ${ }^{4}$

Sí, que haya vida, por supuesto. Peter Brook hablaba mucho de calidad. Un movimiento puede ser simplemente un movimiento o puede tener calidad. Y cuando tiene calidad, entonces cobra vida. Lo mismo ocurre con una palabra, con un gesto, o con la danza, de repente cobran vida, pero si no tienen aquello de lo que hablas, entonces no. Es cierto, es cuestión de ritmo, porque cuando la obra está viva hay una pulsación. De hecho, la naturaleza de la realidad y de la vida es la vibración, el ritmo, el movimiento, la danza. El ritmo atraviesa todo lo que hacemos, todo lo que somos, si no hay ritmo en nuestro corazón no vivimos. Como te he mostrado antes, me fascinan los descubrimientos de la física cuántica y de la astrofísica que coinciden con las filosofías espirituales que existen desde hace mucho tiempo. Como el hecho de que la naturaleza de la realidad es energía, vibración, en las partículas más elementales no hay nada más. El conjunto del universo se reduce a esto. Creo que detrás de todas las imágenes, los símbolos, los arquetipos de todas las tradiciones antiguas, está esto. Śiva, el creador que lleva un damaru en su mano, es una imagen simbólica muy bonita y comunicativa para decir lo mismo. El mundo comienza a partir de una vibración ${ }^{5}$ [5].

En el arte buscamos esto mismo, estar despiertos, sentirnos vivos. Podemos llamarlo como queramos: vibración, calidad, ritmo. En definitiva, buscamos un estado de percepción, de consciencia, de atención verdaderamente poderoso. Cuanto más despiertos estamos más claramente podemos comunicarnos con los demás. Para mí, el arte, la danza, la música son energías, una suerte de catalizadores verdaderamente poderosos que pueden propulsarnos. Pero creo que todos buscamos esto mismo en cada instante de la vida, no solo en escena. Hay una continuidad, la vida, la escena, son una misma cosa.

(Damos la entrevista por concluida. Hablamos un rato de manera informal, me pregunta por mis investigaciones con la intención de encontrar el vínculo y el interés que muestro hacia su trabajo. Pero justo antes de comenzar a despedirnos, me dice:)

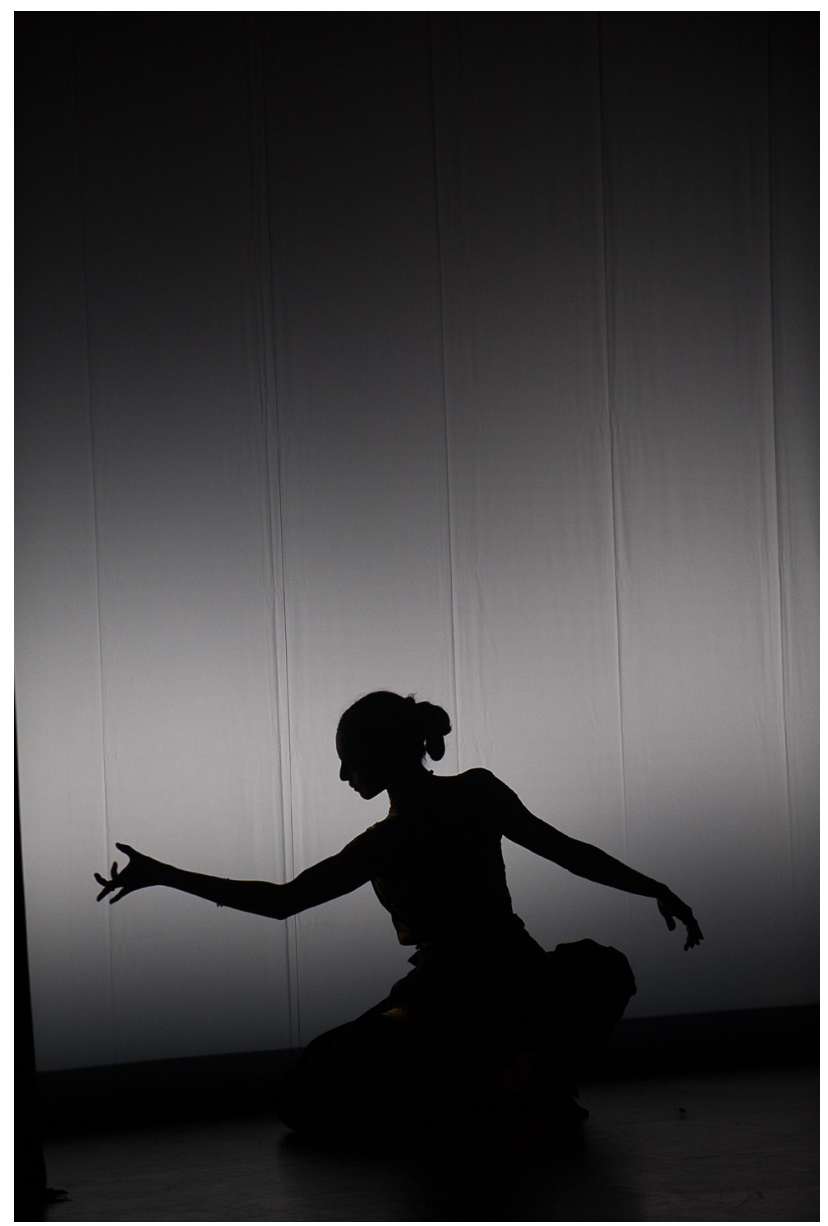

5. Shantala Shivalingappa en Akasha (fotografía de Cristopher Duggan)

Espera, oyéndote hablar he pensado en otra idea de la que hablaba Peter Brook, y sobre todo Yoshi Oida, uno de sus actores: el acto de desaparecer. Yoshi me contaba que cuando era pequeño le gustaba mucho jugar a esconderse en un saco negro y su madre hacía que le buscaba. Parece paradójico que alguien a quien le gusta desaparecer se suba sobre un escenario ante todo el mundo. Pero, me decía: «es lo mismo, porque en escena desaparecemos. Si hablo de la luna y me veis, he perdido; si veis la luna y ya no me veis más, he ganado. Cuando desaparezco la luna cobra vida en escena». Esto es clave. En la danza me ocurre lo mismo, busco desaparecer. Como individuo me pongo de lado y entonces puedo recrear infinidad de cosas, pues ya no soy yo la que estoy ahí. Hay que dejar 
de ser un obstáculo en el camino, volverse transparente. Cuando nos volvemos transparentes el mundo se hace visible. Mi maestro de Kūcipūọi también hablaba de esto. Todos los grandes dicen lo mismo (risas). Decía que hay que ser como una tela inmaculada de manera que cada color que añadimos se pueda ver. Si en ella incorporamos rojo vemos el rojo en todo su esplendor, pero si la tela ya tiene color no podemos ver las cosas con nitidez, así que me decía- «tienes que ser una tela totalmente inmaculada, este es tu trabajo».

\section{Notas}

1 Esta entrevista ha sido realizada gracias a un contrato predoctoral del MINECO-UCM y a una ayuda de movilidad vinculada al mismo programa que facilitó una estancia de investigación de cuatro meses en el Centre d'études de l'Inde et de l'Asie du Sud de París.

2 Tanto el Kücipūdi como el Bharatanātyam son dos estilos clásicos de danza india, el primero originario de Andhra Pradesh y el segundo de Tamil Nadu, aunque ambos se practican en diversos lugares del país. Una de las mayores particularidades de la danza clásica india es su aspecto narrativo. Además de estar compuesta de pasos y movimientos, el bailarín, mediante un complejo código gestual, es capaz de contar historias empleando únicamente su cuerpo. Este lenguaje, que recibe el nombre de abhinaya, está configurado principalmente por los gestos de las manos (hasta y mudrā), así como por los movimientos del cuerpo y de las distintas partes del rostro (cejas, ojos, boca, mentón, mejillas, cuello, etc.). Con el pertinente dominio de la técnica del abhinaya el bailarín logra transmitir infinidad de matices expresivos a través de su danza.

3 La totalidad de la entrevista se realiza en francés, y ella traduce la palabra wonder como émerveillement.

4 Véase el libro colectivo del proyecto I+D Trama (Aizpún, Teresa, Ibáñez, Cayetana y Fernández del Campo, Eva (Eds.), 2015).

5 El damaru es el pequeño tambor que Śiva, en su imagen de Nātarāja («Rey de la danza»), lleva en su mano superior derecha. Esta imagen representa una danza destructora que, en la concepción cíclica de la existencia hindú, es también creadora. Esta danza cósmica comienza a partir del primer ritmo generado por ese tambor que pone en funcionamiento todas las partículas del universo. En su espectáculo Akasha, Shantala Shivalingappa dedica una pieza a esta imagen de Śiva. La coreografía comienza con su sombra proyectada en una pantalla blanca, con su mano derecha realiza un mudra (gesto) como si en ella llevara el damaru, un tambor empieza a sonar y su mano comienza a vibrar.

\section{Bibliografía}

AIZPÚN, Teresa, IBÁÑEZ, Cayetana y FERNÁNDEZ DEL CAMPO, Eva (Eds.) (2015), Ritmo: el pulso del arte y de la vida, Abada, Madrid.

BROOK, Peter (2003), Hilos de tiempo, Siruela, Madrid (1. ${ }^{a}$ edición en inglés 1998).

- (2010), La puerta abierta. Reflexiones sobre la interpretación y el teatro, Alba Editorial, Barcelona (1. . edición en inglés 1993).

MATISSE, Henri (1908), «Notes d'un peintre», en MATISSE, Henri (2005), Écrits et propos sur l'art, Hermann, París, pp. 39-53.

BROOK, Simon (dir.), BROOK, Peter y BROOK, Simon (guion), The Tightrope, 2012. 